\title{
Study on the Appearance and Peel Strength of Byakudan-Nuri Works
}

\author{
Chieko Narita $^{1}$, Atsushi Endo ${ }^{1}$, Yutaro Shimode ${ }^{2}$, Kazushi Yamada ${ }^{{ }^{*}}$ \\ ${ }^{1}$ Department of Advanced Fibro-Science, Kyoto Institute of Technology, Kyoto, Japan; ${ }^{2}$ Kyoto Research Institute of Natural Lacquer \\ Cultural Properties, Kyoto, Japan. \\ Email: "kazushi@kit.ac.jp
}

Received December $13^{\text {th }}$, 2013; revised January $18^{\text {th }}, 2014$; accepted January $29^{\text {th }}, 2014$

Copyright (c) 2014 Chieko Narita et al. This is an open access article distributed under the Creative Commons Attribution License, which permits unrestricted use, distribution, and reproduction in any medium, provided the original work is properly cited. In accordance of the Creative Commons Attribution License all Copyrights (C) 2014 are reserved for SCIRP and the owner of the intellectual property Chieko Narita et al. All Copyright (C) 2014 are guarded by law and by SCIRP as a guardian.

\section{ABSTRACT}

This paper focuses on Byakudan-nuri, one of the traditional decoration techniques of Japanese Urushi (Urushi natural lacquer) crafts. Works produced by Byakudan-nuri express a unique luster color owing to painting gold or silver leaves along with highly transparent Urushi. The specific problem of Byakudan-nuri is the exfoliation of Urushi off the metal leaf surface, to solve a lot of repair work which is done nowadays. For Byakudan-nuri, silver leaf is preferred to a gold leaf. This paper tries to clarify the influence of the different kinds of metal leaves on the appearance and peel strength of works of Byakudan-nuri and, moreover, to elucidate the reason why silver leaf has been used more frequently for Byakudan-nuri until now. It was found out that the reason for the more frequent use of silver leaf in Byakudan-nuri is that silver does not seem to affect the appearance and peel strength in works produced by this technique.

\section{KEYWORDS}

\section{Urushi (Urushi Natural Lacquer); Gold Tooling; Byakudan-Nuri; Traditional Crafts}

\section{Introduction}

The gold leaf has a long history and has been already made and used for fashion and decorative objects in Egypt in about 1200 B.C. [1]. Now, gold leaf is used in a wide range of fields such as arts, architecture and decoration of industrial goods all over the world [2-5].

In Japan too, the technique of gold tooling has been used for a long time, as shown in "Urushi kinpakue no ban" as part of the Shoso-in treasures [6]. Glue and synthetic resins are used as adhesives for gold leaves used for arts or architecture. However, Urushi is used as an adhesive for gold leaves in the case of traditional crafts like Buddhist altar fittings. In this field of Urushi craft, Ohgaku and Wada already researched the material properties of gold leaf [7-9]. In addition, Tsurusako focused on the darkness of gold leaves in the Kinkaku-ji Temple, a world heritage site. As a result, the appearance of gold leaves, used for architectural decoration, may have

\footnotetext{
${ }^{*}$ Corresponding author.
}

changed by alloy formation, in particular by a solid-solid reaction between gold film and lead particles [10].

However, whereas there is abundant research material on the material properties of gold leaf itself, the same cannot be said about the state of gold leaf after processing of crafts [11]. The lack of research about the material properties after processing could become a serious problem in the future from the viewpoint of preservation and restoration of cultural assets, as well as for manufacturing.

In this study, Byakudan-nuri, which is one of the traditional decoration techniques of Japanese Urushi craft, was studied using the results of our past research. Byakudan-nuri work expresses a unique luster color because of painting a gold or silver leaf with highly transparent Urushi. Examples of its use can be found in the works of art produced during the Heian period (794 - 1185 A.D.). It is thought that the technique was affected by Chinese lacquer-ware [12]. As described above, a gold or silver leaf is used for the undercoat of Urushi in Byakudan-nuri. 
However, there is no research on the influence of different under coatings on the material properties of the craftwork as yet. Besides, exfoliation between leaf and Urushi may easily occur, and represents the main problem of Byakudan-nuri. Therefore, a lot of repair work of Byakudan-nuri handicrafts is being undertaken nowadays. It is important to investigate the cause of this problem for the preservation and restoration of Byakudan-nuri. Interestingly, silver leaf is used in almost all damaged works of Byakudan-nuri, as shown in Figure 1.

Therefore, we aim to clarify the following two subjects in this paper:

- The influence of the different kinds of metal leaves on the appearance and peel strength of Byakudannuri.

- The reason why silver leaf is used much more frequently in Byakudan-nuri.

\section{Experimental}

\subsection{Materials}

Gold leaves are classified according to their compositional ratio of gold, silver, and copper. Six kinds of Byakudan-nuri specimens were used in this experiment, as shown in Table 1. Five gold leaves with different compositional ratios and one pure silver leaf were used.

The gold leaf is also classified according to the two kinds of manufacturing methods. One is the traditional method named "Entsuke", and the other is the modern method called "Tachikiri". According to Ohgaku's research that compared Entsuke and Tachikiri, the surface

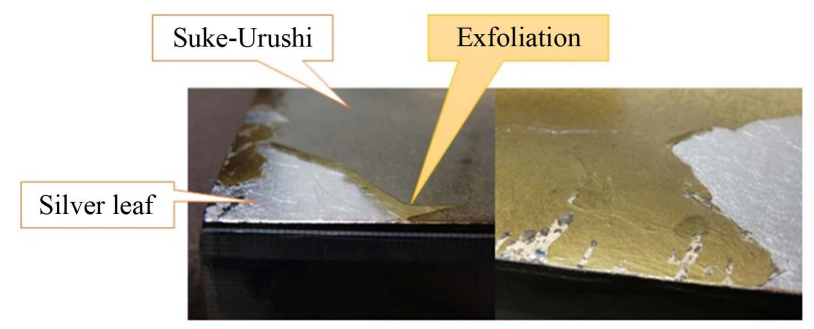

Figure 1. Example of a repaired work of Byakudan-nuri, made using silver leaf.

Table 1. Compositions of the gold and silver leaves used.

\begin{tabular}{ccccc}
\hline Specimen & Leaf type & Gold & Silver & Copper \\
\hline A & Gold leaf (5 mou) & 98.91 & 0.50 & 0.59 \\
B & Gold leaf (1 gou) & 97.67 & 1.36 & 0.98 \\
C & Gold leaf (2 gou) & 96.72 & 2.41 & 0.87 \\
D & Gold leaf (3 gou) & 95.80 & 3.34 & 0.86 \\
E & Gold leaf (4 gou) & 94.44 & 4.90 & 0.66 \\
F & Pure silver leaf & 0 & 100 & 0 \\
\hline
\end{tabular}

pattern and thickness of the leaf were somewhat different [8]. Gold leaf is manufactured by hammering a goldalloy sheet repetitively. Then, extremely thin parts, less than $0.1 \mu \mathrm{m}$ in thickness, and thicker parts, more than $0.15 \mu \mathrm{m}$ in thickness, are produced by both manufacturing methods. All gold leaves used in this experiment were of the Entsuke type (IMAIKINPAKU CO., LTD.).

The manufacturing method of silver is the same as that of a gold leaf. However, the thickness of silver is a bit larger than that of a gold leaf. The thickness of silver leaf is about $0.2 \mu \mathrm{m}$ whereas the thickness of gold leaf is about $0.1 \mu \mathrm{m}$. The structural scheme of Byakudan-nuri is shown in Figure 2.

\subsection{Testing Methods}

\subsubsection{Colorimetry and Glossiness}

A spectral colorimeter (SQ-2000, NIPPON DENSHOKU INDUSTRIES CO., LTD.) was used for colorimetry in order to measure $\mathrm{L}^{*}, \mathrm{a}^{*}, \mathrm{~b}^{*}$, and $\mathrm{C}^{*}$ values. The $\mathrm{L}^{*} \mathrm{a}^{*} \mathrm{~b}^{*}$, or CIELab, color space is an international standard for color measurements, adopted by the Commission Internationale d'Eclairage (CIE) in 1976. $\mathrm{L}^{*}$ is the luminance or lightness component, which ranges from 0 to 100 , and parameters $\mathrm{a}^{*}$ (from green to red) and $\mathrm{b}^{*}$ (from blue to yellow) are the two chromatic components, which range from 120 to 120 . C* value which is calculated from a* and $\mathrm{b}^{*}$ is corresponding to a chroma. A glossimeter (IG-410, HORIBA, Ltd.) was used to measure the glossiness in the measurement range of $0-1000$.

\subsubsection{Peel Strength}

SAICAS (surface and interfacial cutting analysis system, DN, DAYPLA WINTES CO., LTD.) was used to measure the peel strength. The measurements were performed in a constant speed mode (vertical velocity $5 \mu \mathrm{m} / \mathrm{s}$, hori-

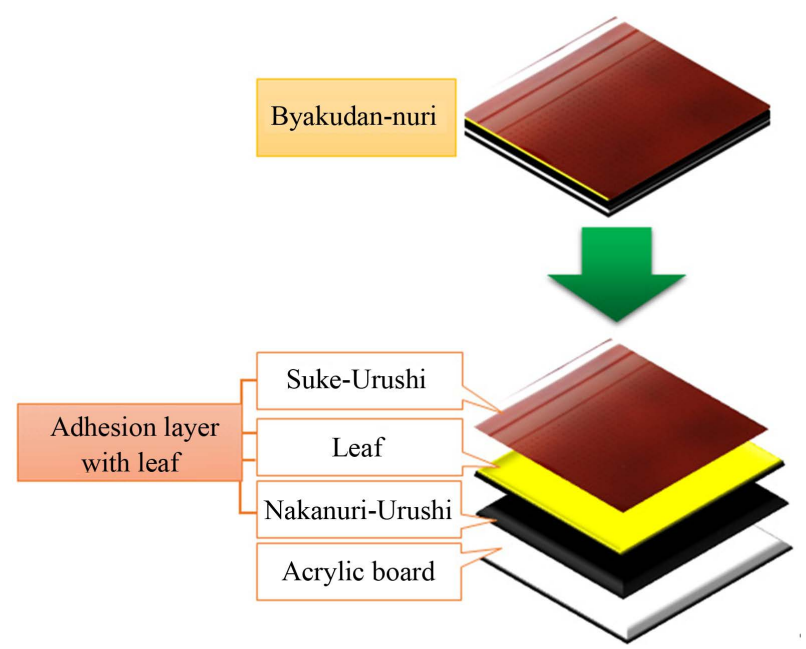

Figure 2. Structural scheme of the traditional decoration technique Byakudan-nuri. 
zontal velocity $0.05 \mu \mathrm{m} / \mathrm{s}$ ). A digital microscope (VHX900, KEYENCE Japan) was used for the fractographic study of the SAICAS experiments.

It should be noted that Byakudan-nuri uses two adhesion layers with the metal leaf between them, as shown in Figure 2, and exfoliation involves both these two adhesion layers, as shown in Figure 3.

The yellow area is gold leaf and the black area is Nakanuri Urushi in Figure 3. The experimental subject of this study was the peel strength between Suke-Urushi and the metal leaf (upper layer) in order to evaluate the damaged state of the specimen, as shown in Figure 1.

\section{Result and Discussion}

\subsection{Colorimetry and Glossiness}

The $\mathrm{L}^{*}, \mathrm{a}^{*}, \mathrm{~b}^{*}$, and $\mathrm{C}^{*}$ values of all specimens are shown in Figure 4. From the results of colorimetry, pro- nounced differences in the $\mathrm{L}^{*}, \mathrm{a}^{*}, \mathrm{~b}^{*}$, and $\mathrm{C}^{*}$ values among the different samples could not be observed. Shimode compared the colorimetry of gold-tooling specimens to obtain values between Specimen A and E. The degree of the pureness of gold was high, and there were only slight differences in the $b^{*}$ and $C^{*}$ values [11]. It is considered that the color of gold leaf did not influence the colorimetric results, in contrast to Suke-Urushi, which exhibited a clear influence because there were no differences in the $b^{*}$ and $C^{*}$ values of the samples with different compositional ratios of gold. This inference is suggested by the fact that, overall, there were only a few differences in the colorimetric values of the different silver and gold leaves.

Likewise, the glossiness of the specimens is also not influenced by the variations in the compositional ratios of gold or slight differences in the number and composition of various gold and silver leaves, as evidenced by

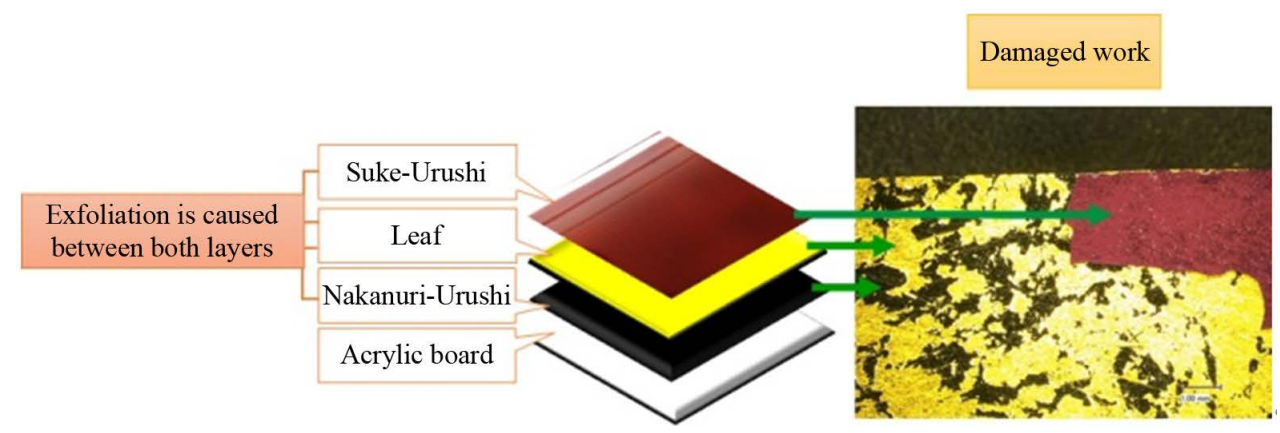

Figure 3. Byakudan-nuri work from which Urushi lacquer and gold leaf were exfoliated.

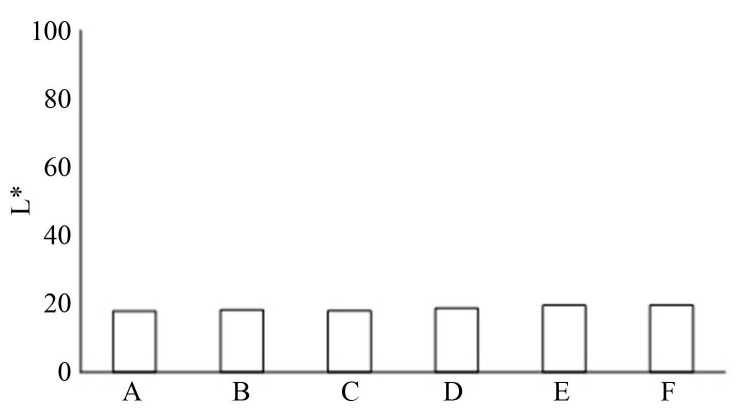

(a)

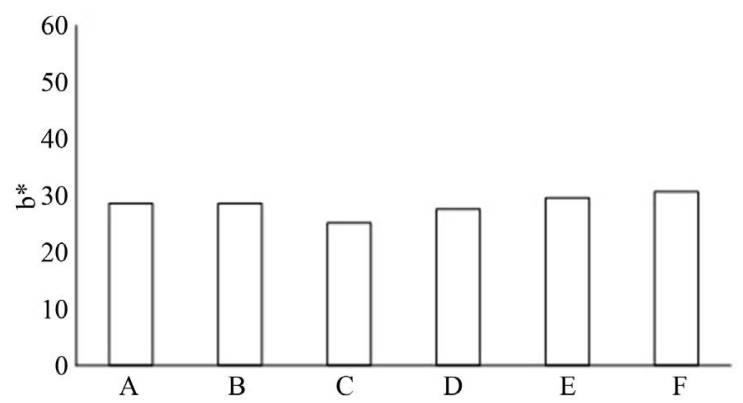

(c)

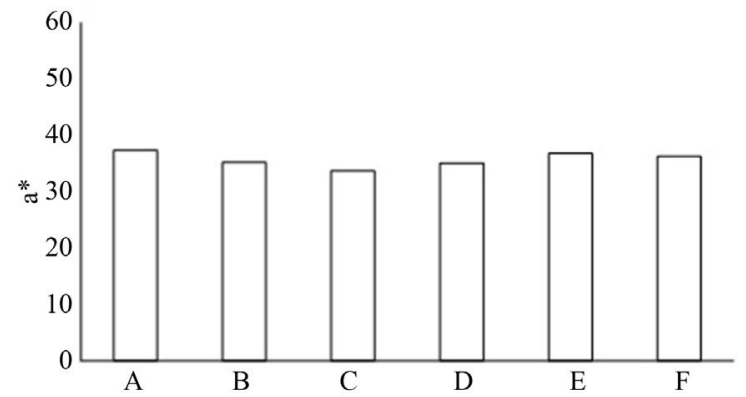

(b)

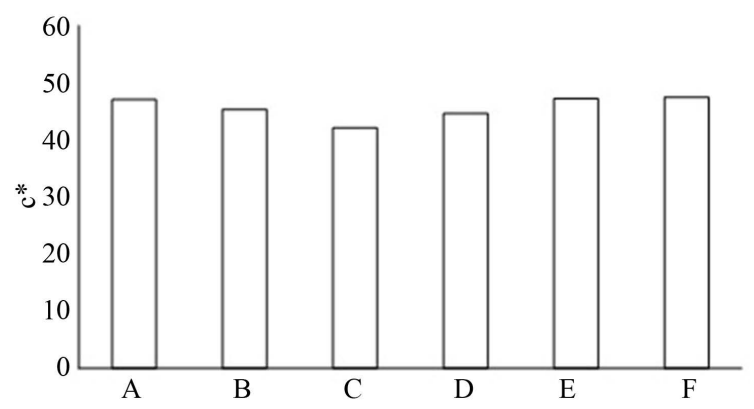

(d)

Figure 4. (a) $\mathbf{L}^{*}$, (b) $\mathbf{a}^{*}$, (c) $\mathbf{b}^{*}$, and (d) $\mathrm{c}^{*}$ values of all specimens. 
Figure 5.

Thus, the present results indicate that the appearance of a Byakudan-nuri work is not influenced by differences in the metal leaf, even if a silver leaf is used instead a gold leaf.

\subsection{Peel Strength}

The scheme of the peeling test by SAICAS is shown in Figure 6. The state of the metal leaf during the peeling test is shown in Figure 7, and the picture of the surface after peeling is shown in Figure 8.

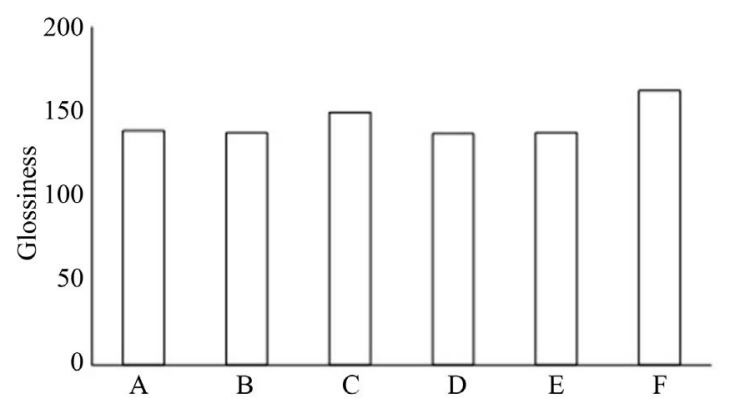

Figure 5. Glossiness of all specimens.

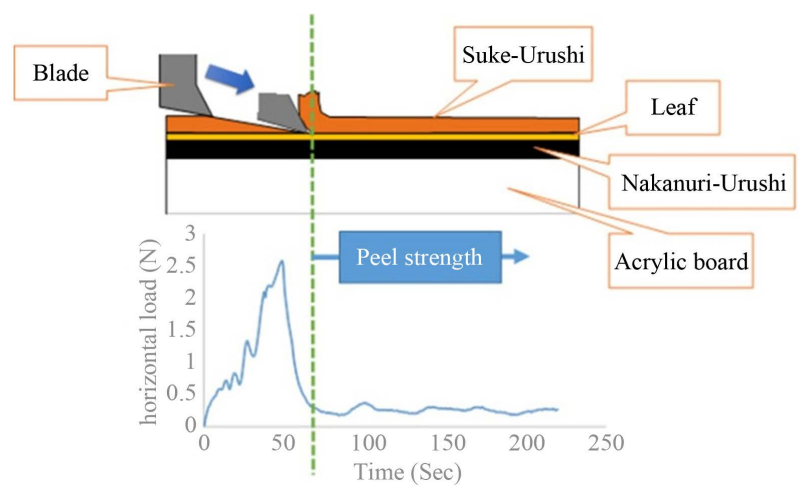

Figure 6. Scheme of the peeling test by SAICAS.

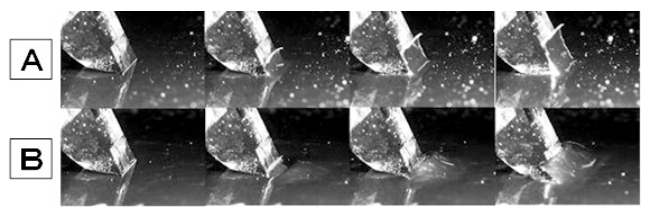

Figure 7. Peeling of gold leaf in case of (A) non-propagative exfoliation and (B) propagative exfoliation.

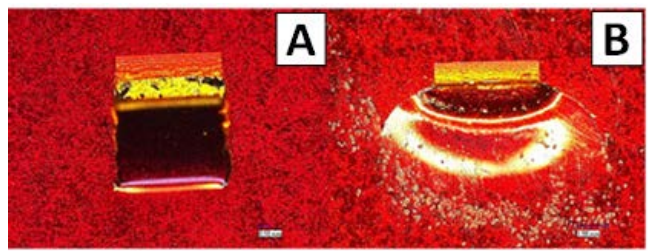

Figure 8. Surface observations of gold leaf in case of (A) non-propagative exfoliation and (B) propagative exfoliation.
Two exfoliation types were observed between SukeUrushi and metal leaves, as shown in Figures 7 and 8. In the case of exfoliation of type (A), exfoliation took place only on the part which was hit by the SAICAS blade. In contrast, exfoliation of type (B) propagated from the blade.

Load-depth curves of exfoliation of type (A) of all investigated samples are shown in Figure 9 and the corresponding peel strength values of all specimens are listed in Table 2.

The results are restricted to exfoliation of type (A) because it is impossible to quantitatively compare the peeling strength between non-propagative and propagative exfoliation. Based on the results presented in Table 2, the peel strength between Suke-Urushi and metal leaf was almost the same, regardless of the kind of metal leaf used or the compositional ratio of gold. Moreover, it is indicated that the peel strength between Suke-Urushi and metal leaf is extremely weak because propagative exfoliation could be easily induced in each of the investigated specimens.

The cost of silver leaf is much lower (a fifth) than that of gold leaf. Therefore, it is obvious that a silver leaf is preferred and used much more frequently for Byakudannuri considering its moderate cost and the fact that there was no difference in the appearance and peel strength.

\section{Conclusions}

This paper tries to clarify the influence of different kinds

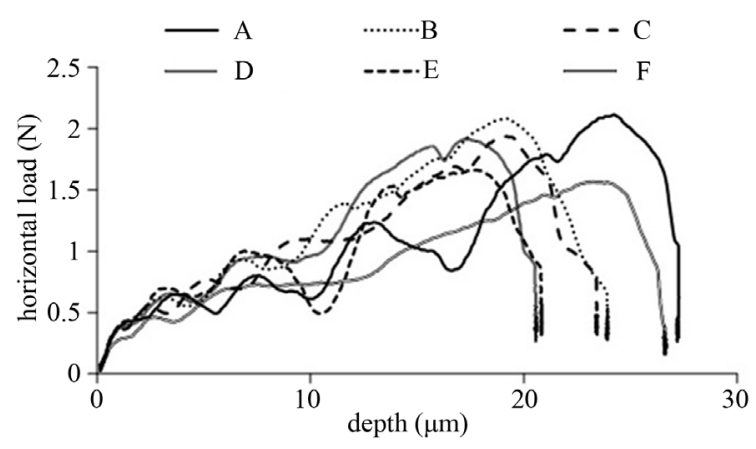

Figure 9. Load-depth curves for each specimen.

Table 2. Peel-strength values of the different specimens for exfoliation of type (A).

\begin{tabular}{ccc}
\hline Specimen & Leaf type & Peel strength (N/mm) \\
\hline A & Gold leaf (5 mou) & 0.759 \\
B & Gold leaf (1 gou) & 0.71 \\
C & Gold leaf (2 gou) & 0.767 \\
D & Gold leaf (3 gou) & 0.482 \\
E & Gold leaf (4 gou) & 0.847 \\
F & Pure silver leaf & 0.706 \\
\hline
\end{tabular}


of metal leaves on the appearance and peel strength of Byakudan-nuri works and to find out the reason why silver leaf is preferred to a gold leaf for Byakudan-nuri.

It is shown that differences in the kind of metal leaf do not affect the appearance of Byakudan-nuri because no significant differences in the color and glossiness of Byakudan-nuri could be observed, irrespective of the type of leaf used (gold or silver). In contrast, the color and glossiness of Byakudan-nuri was affected by the Urushi layer. Similarly, the compositional ratio of gold and the kind of metal leaf hardly affected the peel strength. Therefore, it is concluded that the reason why silver leaf is used much more frequently in Byakudannuri is that the appearance and peel strength are not affected.

\section{Prospect}

The results of this paper show new findings regarding the relationship between metal leaf and Urushi. Also, the weakness of the peel strength between metal leaf and Urushi is substantiated. The weakness of the peel strength does not reveal the flimsiness of Byakudan-nuri directly despite its use for decorating objects of daily use, such as Japanese soup bowls and chopsticks. However, sustained study is required to clarify the peeling mechanism between the metal leaf and Urushi. The results may be applied for the repair of cultural assets in the future because exfoliation between the metal leaf and the Urushi layer is the main reason for damage of Byakudan-nuri works.

\section{Acknowledgements}

The authors wish to thank sincerely Prof. H. Hamada of Kyoto Institute of Technology for his cooperation and K. Maeda of Kyoto Institute of Technology for his kind help with the experiments. The authors express their appreciation to the members of Shimode Maki-e studio for their kind supply of samples for our study.

\section{REFERENCES}

[1] National Mining Association, “The History of Gold”. http://www.nma.org/pdf/gold/gold_history.pdf

[2] L. B. Hunt, “The Early History of Gold Plating,” Gold Bulletin, Vol. 6, No. 1, 1973, pp. 16-27. http://dx.doi.org/10.1007/BF03215178

[3] E. D. Nicholson, "The Ancient Craft of Gold Beating," Gold Bulletin, Vol. 12, No. 4, 1979, pp. 161-166. http://dx.doi.org/10.1007/BF03215119

[4] A. Oddy, "Gilding through the Ages," Gold Bulletin, Vol. 14, No. 2, 1981, pp. 75-79. http://dx.doi.org/10.1007/BF03214601

[5] D. K. Strahan and C. A. Maines, "Lacquer as an Adhesive for Gilding on Copper Alloy Sculpture in Southeast Asia," In: T. Drayman-Weisser, Ed., Gilded Metals: History, Technology and Conservation, Archetype Publications, London, 2000, pp. 185-201.

[6] Nara National Museum, "Catalogue of the 65 Annual Exhibition of Shōsō-in Treasures," Special Exhibition, 2013, p. 49.

[7] T. Ohgaku, "Kinpaku no busseinikansurukisotekikenkyuKinpaku no kougakutekikenkyu-(in Japanese),” Kanazawa-Haku Research Center, 2010. http://www.kanazawahaku-giken.jp/pdf/jigyou_pdf05.pdf

[8] T. Ohgaku, "Kinpaku no busseinikansurukisotekikenkyuKougakutekishuhouwomochiitakinpaku no keijyoukeisoku-(in Japanese),” Kanazawa-Haku Research Center, 2011.

http://www.kanazawahaku-giken.jp/pdf/jigyou23_t.oogak u.pdf

[9] T. Wada, N. Takahashi, M. Demura and T. Kameyama, "La Feuille d' or et ses HAKU-UCHIGAMI-L'ancien Papier Japonais en Frappant de Feuille d'or,” The Clay Science Society of Japan, Vol. 42, No. 2, 2002, pp. 89-96.

[10] T. Tsurusako, H. Suzuki, Y. Saito and C. Kaito, “Alloy Formation by Solid-Solid Reaction between Gold Film and Lead Particle,” Journal of the Japanese Association for Crystal Growth, Vol. 30, No. 2, 2003, pp. 53-58.

[11] M. Shimode, C. Narita, A. Endo, Z. Suganami, J. Oka, M. Ito and Y. Shimode, "Study on Coloring Effect of Gold Tooling," Proceedings of the 56th Japanese Congress on Materials Research, Kyoto, 2013, pp. 149-150.

[12] K. Shuppan, "ShitsugeiGiten,” KougeiShuppan, Tokyo, 2004, p. 272. 